\title{
O renascer do regime superficiário: a superfície funcionalizada
}

\author{
Roberto Wagner Marquesi ${ }^{1}$ \\ Ana Cláudia C. Zuin Mattos do Amaral ${ }^{2}$ \\ Miriam Odebrecht Carvalho de Mendonça ${ }^{3}$
}

\section{Resumo}

\begin{abstract}
Abordagem do direito de superfície, com análise de seu conceito, natureza jurídica, evolução histórica e efeitos. Este artigo empreende um estudo calcado na interdisciplinaridade da norma civil com as normas urbanística, agrária e constitucional no tocante àquele instituto, à luz do princípio da função social dos direitos reais.
\end{abstract}

Palavras-Chave: Superfície; Direitos Reais; Função Social.

\section{Introdução}

Com a entrada em vigor do Código Reale, o elenco dos direitos reais limitados foi alterado com a eliminação da enfiteuse e o ingresso da superfície. Cuidando-se de tema novo, embora não inédito no direito brasileiro, o instituto está a despertar a atenção do civilista, especialmente daquele que se debruça sobre a complexa temática da função social da propriedade.

Os novos paradigmas dos direitos reais impõem sua abordagem à luz do Texto Constitucional. E, nesse sentido, vindo para substituir a obsoleta figura da enfiteuse, a introdução do direito real superfície assinala a orientação do sistema jurídico em direção à natureza funcionalizante dos direitos reais.

Investigar o conceito e a natureza jurídica do regime superficiário, promovendo-lhe a abordagem histórica e o contraste com outros institutos, é tarefa necessária para apurar se o delineamento do instituto é apto a atingir o predicado da função social dos direitos reais, erigido à categoria de princípio no Texto de 1988.

1 Doutorando em Direito Civil pela USP, Largo de São Francisco. Mestre em Direito Negocial pela UEL. Professor dos Cursos de Graduação e Pós-Graduação em Direito Civil da UEL;

2 Mestre em Direito Negocial pela UEL. Professora dos Cursos de Graduação e Pós-Graduação em Direito Civil da UEL;

3 Quintanista do Curso de Graduação em Direito; 
Mercê de sua natureza interdisciplinar, na medida em que transita por normas civis, urbanísticas, agrárias e constitucionais, o tema impõe tratamento complexo, o que torna ainda mais instigante ao pesquisador a tarefa de apreender-Ihe a essência e compreenderIhe a função socializante.

Por isso, o presente discurso é dividido em duas partes. Na primeira, cuidam-se dos aspectos basilares do regime superficiário, enquanto, no segunda, trata-se de sua dinâmica e da aptidão para atingir o compromisso constitucional da funcionalização urbana e rural dos imóveis.

\section{Conceito e natureza jurídica}

Os arts. 1.253 e ss. do Código Civil consagram a milenar regra segundo a qual as construções e plantações pertencem ao dono do solo onde foram realizadas. Trata-se do velho princípio romano superficies solo cedit, a significar que a superfície acede ao solo. 0 sentido jurídico do vocábulo "superfície", advirta-se desde logo, não corresponde ao seu significado etimológico. Na acepção comum, a superfície é aquilo que está na face superior de algo e, nesse sentido, a superfície é o próprio solo. Juridicamente, contudo, entende-se como superfície aquilo que emerge do solo, ocupando o espaço aéreo sobrejacente, tais os casos das construções e das plantações. Umas e outras deitam raízes e fundações no solo; logo, a este se agregam, tornando-se propriedade do dono do terreno. Por força do princípio da acessão, o solo e as respectivas construções e plantações pertencerão, em regra, ao mesmo sujeito.

O direito de superfície, disciplinado a partir do art. 1.369 do Código Civil e dos arts. 21 e ss. do Estatuto da Cidade (Lei 10.257/2001), suspende a eficácia do princípio de que as acessões são propriedade do titular do terreno. Permite esse instituto a constituição, num mesmo espaço físico, de duas propriedades distintas: o domínio do solo e o domínio superficiário, de sorte a que o terreno e as acessões, agora ficticiamente separados entre si, pertencerão a titulares diferentes. O que de fato se verifica é uma superposição de domínios, cada um deles a ser exercido numa dimensão distinta, vale dizer o solo e o espaço aéreo a ele sobrejacente. Assim, segundo a disciplina geral, se um terceiro constrói casa em terreno alheio, ao dono deste a casa se incorpora, mas, convencionada a superfície, a casa 
pertencerá a um sujeito (superficiário), enquanto o solo permanecerá com o proprietário original (dono do solo ou fundeiro).

Assim, o direito de superfície surge como direito real sobre coisa alheia, pressupondo a existência de dois titulares sobre um mesmo bem, que neste caso são o superficiário (titular das acessões) e o fundeiro (proprietário do solo). Este último concede ao primeiro o privilégio de plantar e ou construir sobre seu terreno, por tempo determinado ou não e por meio de escritura pública registrada no ofício imobiliário competente.

A superfície constitui-se por concessão do dono do solo, tendo como fonte, portanto, um negócio jurídico. Segundo o Código, terá sempre prazo determinado, embora tal orientação não tenha sido perfilhada pelo Estatuto da Cidade, cujo art. 21 permite indeterminação do termo final. A constituição se dá por escritura pública, mas o registro imobiliário é fundamental para o direito adquirir a eficácia erga omnes típica dos direitos reais. Enquanto não registrada, a convenção gera simples direito pessoal entre as partes. Advindo o termo de vencimento, o superficiário necessariamente terá de entregar a construção ou plantação ao dono do solo, que assim readquirirá ou adquirirá a propriedade sobre elas. Com a transmissão da propriedade superficiária ao fundeiro, que ocorre de pleno direito ao final do prazo, volta a incidir o princípio da acessão, resolvendo a titularidade superficiária e consolidando o domínio nas mãos do dono do solo, que agora passa a ser proprietário pleno. Fixada sem prazo determinado, a superfície se extinguirá com a notificação dirigida ao titular.

Ora, se o direito de superfície, à símile da enfiteuse, é direito de propriedade e se, necessariamente, encontrará termo final, fica clara sua natureza de propriedade resolúvel. Logo, pode ela ser conceituada como o direito real de plantar ou construir em terreno alheio e que concede ao seu titular, o superficiário, a propriedade resolúvel da plantação ou construção, temporariamente e ficticiamente destacadas da propriedade do solo, pertencente a titular diverso. Direito real, porque oponível erga omnes, inclusive contra o dono do solo; direito resolúvel, porque, cedo ou tarde, cairá em mãos do dono do solo; direito temporário, porquanto, ao contrário da enfiteuse, vedada a perpetuidade; direito destacado do domínio do solo, pois com este não se confunde.

Firmado seu conceito e natureza jurídica, impende investigar-lhe a evolução histórica. 


\section{Escorço histórico}

A superfície tem berço romano e nasceu da necessidade de ocupação de espaços físicos, conforme iam aumentando os domínios territoriais do Estado conquistador. Num primeiro momento e à semelhança de um arrendamento por longo prazo, a autoridade romana concedia aos particulares o direito de construir em terreno público. Posteriormente, os próprios particulares põem-se a conceder essa forma de arrendamento a outros particulares, disseminando assim as edificações. A faculdade de construir em terreno alheio, contudo, não gerava ao titular um direito real, porquanto limitada ao campo obrigacional dos contratos e circunscrita ao princípio da acessão.

Com o passar do tempo, o pretor passa a conferir proteção possessória ao concessionário, através do interdito de superficiebus. Mercê da tutela interdital, a superfície acaba por assumir o caráter de um direito real, oponível erga omnes (MOREIRA ALVES, 2004, p. 346-347). Sob Justiniano (527-565 d.C.), o instituto firmar-se-á como direito real sobre coisa alheia, como se vê do Digesto (XLIII,18,1). Ao superficiário são atribuídas ações reais, como a ação de superfície, semelhante à reivindicação; a ação confessória, destinada a demonstrar sua titularidade e a ação negatória, para declarar a inexistência de ônus sobre a coisa (BRAGA TEIXEIRA, 1993, p. 20).

Na Idade Média, o instituto conheceu, assim como a enfiteuse, enorme expansão. Isso se deveu, particularmente, a dois fatores: a influência da Igreja Católica, ávida de legitimar as construções que fizera em solo público e particular e o caráter nômade dos povos bárbaros, a valorizar mais o trabalho que o solo onde este se exercia. As incursões germânicas e a conseqüente necessidade de defesa dos territórios impõem uma reorganização na forma de ocupação da terra, a gerar uma ruptura do modelo fundiário, agora baseado na superposição de domínios. Vários titulares exercem poderes em graus diferentes, segundo o critério da concessão por títulos nobiliárquicos. Enfiteuse e superfície, por permitirem essa pluralidade de titulares sobre um mesmo imóvel, são os mecanismos que melhor atendem à nova ordem. Essa época assinala, inclusive, o nascimento da superfície sobre plantações.

A disseminação do modelo superficiário e enfitêutico traz consigo, contudo, a servidão humana e a vassalagem, pelas quais o trabalhador se transforma num agregado da terra, devendo obediência irrestrita ao senhor feudal. A superfície do medievo, tal como a 
enfiteuse, porque atentatórias da liberdade individual, constituirão forte argumento para os ideólogos da Revolução Francesa. Assim é que o Código Napoleão, de 1804, nada dispôs sobre um e outro instituto, preferindo esquecê-los para acentuar o exclusivismo do direito de propriedade e evitar um retorno aos perfis medievais.

O advento do Código Civil Austríaco, em 1811, assinala o reingresso da superfície nos sistemas europeus, opção que é seguida pelos Códigos holandês (1824), alemão (1896), suíço (1907), italiano (1942) e português (1966) ${ }^{5}$. França, Bélgica e Espanha admitiram-na em leis especiais (BRAGA TEIXEIRA, 1993, p. 25-44). Na América Latina, o instituto está presente nas legislações cubana e peruana. O Código Civil Argentino não a contemplou, mas uma lei do ano de 2001 introduziu a superfície sobre florestas, à semelhança do sistema chileno.

No Brasil, a superfície vigeu desde o Descobrimento até 24.9.1864, quando foi abolida pela Lei 1.257. Influenciado pela legislação napoleônica, que consagrara o absolutismo e a exclusividade do domínio, não a contemplou o Código de 1916, a despeito dos esforços da comissão revisora para reintroduzi-la no sistema. O instituto somente renasceria em 2001, quando da edição do Estatuto da Cidade, achando-se afinal positivado no Código Civil de 2002.

\section{Efeitos}

\subsection{Direitos inerentes à titularidade proprietária}

Constituído o direito de superfície, o titular adquire os poderes de uso, gozo, disposição e reivindicação do imóvel (CC, art. 1.228). É-lhe lícito, pois, usar pessoalmente a coisa, habitando-a, ou então alugá-la ou comodá-la. No caso de superfície sobre plantações, pode explorar pessoalmente o solo ou mesmo arrendar ou dar a cultura em parceria a um terceiro. Demais, pode transferir a titularidade, vendendo o bem e com isso deixando de ser superficiário, não se excluindo venha a dá-lo em garantia real. Tem poderes de proprietário, portanto.

4 Art. 952. Costituzione del diritto de superficie. Il proprietário può costituire il diritto di fare e mantenere al di sopra del suolo uma costruzione a favore di altri che ne acquista la proprietà;

5 Art. 1.524. O direito de superfície consiste na faculdade de construir ou manter, perpétua ou temporariamente, uma obra em terreno alheio, ou dele fazer ou manter plantações; 
É o que decorre do referido art. 1.369, que é complementado pelo art. 1.372 do Código, este assim redigido: o direito de superfície pode transferir-se a terceiros e, por morte do superficiário, aos seus herdeiros. Tal transferência, que só produzirá efeitos erga omnes se registrada, poderá dar-se onerosa ou graciosamente, mas, num e noutro caso, nenhuma remuneração será devida ao dono do solo, por força da vedação prevista no parágrafo desse dispositivo. Ao proibir a remuneração do dominus soli nos casos de transmissão da propriedade superficiária, quis o legislador estimular o comércio jurídico e a circulação de riquezas, visando ao cumprimento da função social dos direitos reais. A superfície afasta-se, nesse ponto, da enfiteuse, que exigia o pagamento de um importe (laudêmio) sempre que o domínio útil fosse transferido. Em relação à transferência e sucessão da titularidade, a mesma regra do art. 1.372 é contemplada pelo art. 21, §§ 4‥ e 5‥, do Estatuto da Cidade.

Deve-se destacar, ainda, que, sendo o superficiário titular de direitos reais, tem ele posse sobre a coisa, razão por que poderá manejar os interditos para defendê-la, inclusive contra o dono do solo, que se mantém possuidor indireto, segundo a regra geral do art. 1.197.

\subsection{Direitos defluentes da superfície}

\subsubsection{Tributação}

Derivada de negócio jurídico, a superfície gera também obrigações ao seu titular. Além do dever de pagar a remuneração, caso onerosa a concessão, é ônus do superficiário o pagamento dos impostos incidentes sobre o imóvel. A regra, que decorre do art. 1.371, não é absoluta, pois podem as partes atribuir tal dever ao proprietário do solo. No art. $21, \S 3$ ㅇ., do Estatuto da Cidade, há permissivo expresso a respeito. $O$ art. 1.371 poderia ter sido melhor redigido, uma vez que a expressão imóvel, nele constante, não deixa assente tratarse do imóvel todo ou apenas do imóvel superficiário. Acertada parece a segunda hipótese, pois, sendo o solo e a superfície porções distintas, é razoável que cada titular suporte os respectivos ônus. Mais feliz foi o Estatuto da Cidade, que, no mesmo art. 21, § 3‥, obriga o superficiário ao pagamento dos impostos sobre a construção e sobre a parcela do terreno que efetivamente ocupa. No caso de IPTU, por exemplo, competirá ao município criar 
mecanismos para calcular e lançar impostos distintos para o superficiário e para o dono do solo.

\subsubsection{Destinação}

Deve o superficiário manter a destinação para a qual o direito lhe foi concedido. Se concedida para moradia apenas, não poderá ele transformar a coisa numa loja. Convencionado para fins empresariais, não será lícito habitar o imóvel. Trata-se de obrigação negativa, cujo descumprimento pode gerar a rescisão da concessão, segundo o norte do art. 1.374, litterim: antes do termo final, resolver-se-á a concessão se o superficiário der ao terreno destinação diversa daquela para que foi concedida. Idêntico norte encontra-se nos arts. 23, II e 24 , § 1‥, do EC.

\subsubsection{Restituição da coisa e remuneração}

Exaurido o prazo estipulado ou notificado o titular do término da superfície sem prazo, deverá ele entregar o domínio e a posse direta da construção ou plantação ao fundeiro. Com a entrega e a resolução da propriedade superficiária, volta a incidir o princípio da acessão e o domínio se consolida nas mãos do concedente, que agora é dono do terreno e das respectivas acessões. É o que dispõem o art. 1.375 do Código e o art. 24 do Estatuto da Cidade. Finda a concessão, cumpre distinguir o que foi avençado no instrumento quanto às construções ou plantações. Se as partes houverem convencionado indenização, então caberá ao dono do solo abonar as acessões realizadas pelo superficiário. No silêncio do contrato, não haverá indenização.

Na primeira hipótese, o dono do solo deverá pagar pelas acessões, que afinal se incorporarão ao seu domínio. Mas terá economizado na conservação do imóvel, livrando-se inclusive dos tributos sobre ele incidentes se o contrato o tiver explicitado. A superfície permite ao proprietário de um terreno, que momentaneamente não tem condições de construir ou plantar, manter o imóvel funcionalizado, imunizando-o às sanções decorrentes da não utilização ou subutilização da coisa, o que, na seara urbana, pode levar à desapropriação. O superficiário, de seu turno, uma vez indenizado, livra-se do desconforto de entregar uma coisa graciosamente. 
No segundo caso, embora tenha se privado temporariamente da superfície da coisa, o dono do solo é compensado, porque depois receberá a construção ou plantação sem qualquer ônus para si. Isso é particularmente verdadeiro no tocante às construções, a produzirem um substancial enriquecimento do fundeiro. Esse é um dos fatores que o animam a conceder o direito de superfície e privar-se da posse plena da coisa. Medite-se no seguinte exemplo: um Banco quer instalar uma agência no centro de uma grande cidade. Não encontrando terrenos disponíveis para a compra ou prédios para locação, convenciona, pelo prazo de dez anos, a superfície com o proprietário que não se dispõe a vender o terreno. A instituição financeira constrói o prédio e o utiliza pelo decênio, entregando-o daí ao dono do solo. Este o receberá sem nenhum ônus; a instituição terá desembolsado na construção, mas certamente terá auferido bom lucro em seus negócios ${ }^{6}$. Doutro lado, o dono do solo receberá as acessões sem nenhuma despesa.

\subsubsection{Preempção}

Tanto a superfície como a propriedade do solo são direitos reais. Sendo assim, a preempção ou preferência aplica-se indistintamente a uma e outra na hipótese de alienação. Com efeito, a teor do disposto no art. 1.373 do Código, em caso de alienação do imóvel ou do direito de superfície, o superficiário ou o proprietário tem direito de preferência, em igualdade de condições. No âmbito urbano, igual regra encontra-se no art. 22 do EC. Tais faculdades são inerentes ao exercício dos direitos reais, cujos titulares, em concorrência com terceiros sem vinculação com a coisa, são prestigiados pelo legislador.

Questão que pode suscitar dúvida é a da venda do solo ou do direito de superfície em desrespeito ao direito de preferência. Nem o Código Civil, no Título da Superfície nem o Estatuto da Cidade trazem regras a respeito. Deve-se aplicar, analogicamente, os arts. 504 e 1.322 do Código, que estabelecem o direito de preempção em favor dos condôminos. Embora superficiário e fundeiro não sejam condôminos, acham-se em situação semelhante, porquanto são titulares de bens que se encontram num mesmo espaço físico, ainda que

6 NELSON COSSARI, da Universidade de Santa Fé, Argentina, traz exemplo esclarecedor acerca da superfície: Su funcionamento tiene que ver también con la cultura moderna que, ordinariamente, no da espacio en su seno para obras perdurabeles. A una gran empresa hotelera, por ejemplo, puede interesarle construir y poseer su edificio en superficie, sabiendo que a su término la construcción será obsoleta, y de esa manera, abonar un precio menor por el uso del terreno (www.acader.unc.edu.ar. Sítio consultado em 13.jun.2005). 
distintos. Conseqüentemente, não sendo notificados da intenção da venda, poderão depositar o valor do negócio e adjudicar o bem, desde que o façam no prazo de cento e oitenta dias, contados do registro da escritura, tal como previsto naqueles dispositivos legais.

Outra questão que poderá gerar complexidade repousa na hipótese de desapropriação do imóvel. Se isso ocorrer, manda o art. 1.376 indenizar tanto o dono do solo quanto o dono da superfície, no valor correspondente ao direito real de cada um. Avaliam-se em separado o solo e as acessões e cada titular receberá o respectivo importe. Pergunta-se, porém: caso não tenham as partes convencionado indenização ao superficiário, poderá este ser indenizado pelo poder expropriante? Responde-se negativamente, sob pena de subversão ao princípio que veda o enriquecimento ilícito. Se o superficiário abriu mão do direito de ser indenizado pelas acessões que fizesse, criou no dono do solo uma expectativa de aquisição. Não é lícito frustrá-la, tanto mais porque a desapropriação não foi provocada pelo concedente.

O disposto no art. 1.376, assim como a exegese que dele se faz, deve ser aplicado também à superfície urbana, uma vez que o Estatuto da Cidade silencia a respeito.

\section{A superfície funcionalizada}

Tal como disposta pelo legislador de 2002, a superfície tem nítido propósito funcionalizante, à símile do que ocorre com o direito de propriedade, visto como um direitopoder. E nem poderia ser de outra forma, dado ser o instituto um desdobramento dos poderes dominiais, diferindo da propriedade apenas por seu caráter resolúvel. Isso demonstra, dentre vários outros fatores, a idéia de que o instituto veio para substituir a enfiteuse, igualmente concebida como forma de funcionalização de imóveis urbanos e rurais, mas hostilizada nos tempos presentes em razão de sua natureza perpétua.

Para bem compreender a questão da funcionalização, é interessante volver os olhos ao passado e investigar como variou a concepção proprietária na contemporaneidade. Mais do que um direito, a propriedade é um modo de pensar, um ponto de vista que o Estado, numa dada época e influenciado por variáveis políticas, ideológicas e econômicas, elege como o ideal para a sociedade (GROSSI, 2006, passim). O sistema dos direitos reais brasileiro sofreu fortíssima influência do Código Napoleão, editado em 1804 e cujo escopo fora o de 
assegurar os privilégios de uma burguesia em ascensão. Compreende-se que, sendo a classe burguesa, após a Revolução, a única em condições de titular a propriedade (como se sabe, Clero e Nobreza foram afastados do poder, enquanto a plebe restou esquecida), tenha ela tratado de positivar o direito de propriedade segundo sua conveniência.

Daí o malsinado disposto no art. 554, a estabelecer uma propriedade de modelo absoluto, inviolável e perpétuo, despido de qualquer comprometimento sócio-econômico. A mesma ideologia será adotada pelo Código Beviláqua, cujo art. 524 seguiu fiel ao paradigma napoleônico, tão ao gosto de uma burguesia tupiniquim, da qual a figura do barão do café é o emblema candente. Logo, o paradigma brasileiro de propriedade, ao menos até o advento do Texto de 1988, quando a função social foi erigida ao estado de direito fundamental (art. 5o., XXIII), não destoa da idéia de propriedade absoluta, sem embargo de os Textos anteriores e o Estatuto da Terra já contemplarem a noção de propriedade funcional.

O vocábulo "função", segundo Rodotá (apud GONDINHO, 2000, p. 405), deve ser entendido como o modo concreto de um instituto ou direito de características morfológicas particulares operar no mundo dos fatos. Facilmente se compreende, assim, que os direitos reais são hábeis a desempenhar duas funções: uma particular, a benefício do proprietário; outra, publica, a favor da coletividade abstratamente considerada.

O Código Reale procura adaptar os direitos reais à contemporaneidade, que vê o domínio e seus desmembramentos como um direito-dever. Direito, no sentido de garantidos estarem os poderes de uso, gozo e disposição; dever, porquanto conducentes ao atingimento de objetivos econômicos, sociais e ambientais, seja na esfera rural seja no âmbito da cidade. Como se expressa Nelson Kojranski (apud O NOVO CÓDIGO CIVIL, 2003, p. 986), a socialização da propriedade não importa a supressão da propriedade individual, mas cria a propriedade-função, que atribui ao titular o dever de, primeiramente, empregar sua riqueza para satisfazer as necessidades particulares e, depois, o dever de satisfazer a necessidades comuns, seja de uma coletividade nacional ou de um grupo secundário.

Disso decorre a conclusão de que a superfície, como um desdobramento da propriedade, deve ser encarada sob a perspectiva da funcionalização, e não somente como um direito real. Tal postura conduz ao seu exame como mecanismo portador de uma função social. 
Justificando a inserção do novo instituto no Código, Ricardo Fiúza (apud CÓDIGO CIVIL COMENTADO, 2005, p. 1259) é claro ao assertar que o direito de superfície está ligado, preponderantemente, à função sócio-econômico-ambiental que os direitos reais desempenham no tecido social. Para o relator do Código, "a mola propulsora do direito de superfície é, sem dúvida, o incremento da função social da propriedade e o seu enquadramento para um determinado fim, em sintonia com os preceitos sócio-econômicos, políticos e jurídicos, e com o estado democrático de direito".

Desse pensamento não destoa Dabus Maluf (MONTEIRO, 2003, p. 252) que se posiciona no sentido de que a ausência de uma regulação legal sempre inibiu as pessoas à prática da superfície, um forte meio de funcionalização do solo. Com a reentrada do instituto em nosso sistema, avança-se notavelmente nos planos jurídico, político, social e econômico.

\subsection{Superfície e urbanificação}

O tratamento constitucional referente à função social imobiliária parte da classificação entre imóveis urbanos e imóveis rurais. É o que se vê dos arts. 182 e 186, cujos desdobramentos encontram-se em várias leis ordinárias, das quais as mais importantes são o Código Civil (Lei 10.406-02), o Estatuto da Terra (Lei 4.504-64) e o Estatuto da Cidade (Lei 10.257-01). Logo, a abordagem acerca da função social da superfície deve partir do critério classificador dos imóveis.

No âmbito urbano tem-se que o instituto em apreço pode desempenhar grande papel funcionalizador. É preocupação crescente em nível mundial a sadia qualidade de vida e o bem-estar na cidade. Por isso se observa um rigor cada vez maior do legislador em relação ao projeto de urbanificação, donde avulta a organização do espaço físico nas cidades. Uma corrida de olhos tanto pelo art. 182 do Texto como pelos arts. 5․ ss. do Estatuto da Cidade mostra que a correta utilização do solo constitui um dos principais valores que a lei busca assegurar no espaço urbano.

Particular relevo assume, nesse sentido, aquele dispositivo constitucional. Da leitura de seus incisos percebe-se que a não utilização ou a má utilização do solo dá azo a severas sanções pelo poder municipal, as quais não excluem a desapropriação. Por isso, valoriza-se a edificação do solo urbano, partindo-se da premissa de serem nocivos os espaços ociosos. Em síntese, pode-se afirmar que a mens legis do art. 182 é a de punir o proprietário que não usa 
ou mal usa o imóvel urbano. Estimula-se, destarte, a construção ou a venda para a construção.

O inciso I, par. 4‥, daquele dispositivo, estabelece o dever compulsório de edificar como um dos mecanismos da administração municipal para eliminar os espaços físicos ociosos. Idêntica orientação encontra-se no art. 5‥ do Estatuto da Cidade. Atribuindo ao particular a obrigação de edificar, o poder público almeja à funcionalização, sob o argumento de serem preferíveis imóveis edificados a imóveis ociosos. A uma porque aqueles contribuem para o incremento do paisagismo e da economia; a duas, porque valorizam a cidade e permitem a fixação da pessoa ou empresa ao solo, impedindo vá ela procurar outras cidades para fixar-se.

Ora, sendo a superfície um mecanismo que permite a constituição de dois direitos de propriedade sobre um mesmo espaço, amolda-se ela com perfeição ao disposto no art. 182. Imagine-se um cidadão que, proprietário de um terreno urbano, não reúna condições econômicas de edificar. A alíquota progressiva do imposto predial tornará insustentável a condição de proprietário, a ponto de o cidadão, mesmo a contragosto, ver-se obrigado a alienar a coisa. A superfície permitirá a ele, porém, manter-se dono do solo, porque a edificação compulsória prevista nesse inciso pode ser realizada por um terceiro, que, tornando-se superficiário, conservará o proprietário do solo na sua titularidade.

Imagine-se o caso de uma instituição de ensino superior que deseje instalar o curso de direito numa cidade. Pesquisando, seleciona um imóvel não edificado e promove gestões para adquiri-lo ao proprietário. Este, notificado pelo município para edificar ou não mais suportando a carga tributária, poderá dá-lo em superfície à instituição, num prazo de 20 anos por exemplo. A instituição edificará e, vencido o prazo, entregará ao dono do solo a construção. Tudo isso terá irradiado vários efeitos, como os seguintes: o dono do solo terá se livrado às sanções municipais, porque seu imóvel está agora edificado; o dono do solo terá se furtado ao pagamento dos impostos, porquanto atribuídos estes, por contrato, à entidade superficiária; esta terá se consolidado na praça e poderá agora, findo o prazo, ou adquirir o terreno ou montar instalações em outro espaço, porque já possui clientela conquistada; finalmente, o mais importante, o imóvel terá cumprido a função social, porque agora edificado, gerador de impostos e prestador de serviços, contribuindo com a economia e a educação, além do paisagismo urbano geral. 
E, ainda que o fundeiro não esteja obrigado a edificar, poderá dar em superfície o terreno, permitindo agora a construção por terceiro sem prejuízo de sua titularidade. Nos grandes centros especialmente, o instituto da superfície poderá incrementar, no futuro, a ocupação dos espaços, pois constitui, sem dúvida, mecanismo facilitador do acesso a imóveis ociosos. É de aguardar com certa expectativa os desdobramentos que o engenhoso instituto produzirá nas grandes cidades.

\subsection{Superfície e reforma agrária}

Sem embargo do potencial funcionalizador na cidade, também na seara rural a superfície está predestinada a um relevante papel. Nesse sentido, é interessante ressaltar que o mesmo espírito animador da enfiteuse oitocentista está presente na superfície agrária. Como se sabe, a enfiteuse foi introduzida no Brasil com o propósito de fomentar a ocupação de glebas ociosas, numa época em que o setor mais importante da economia ainda era a agropecuária. Clóvis Beviláqua (1956, p. 267) não deixa dúvida a respeito ao afirmar que o fim econômico do instituto foi o de "facilitar, pela modicidade do preço, o aproveitamento das terras incultas ou abandonadas". E outro não foi o escopo do art. 680 do seu Código.

Cediço que a questão agrária assume no Brasil problema inquietante, fruto de quinhentos anos de uma ocupação territorial mal direcionada, urge a busca de mecanismos de atenuação dos problemas que afligem o campo, dos quais os mais importantes são a violência, a baixa produtividade e a subutilização dos espaços (MARQUESI, 2001, passim). Para atenuar tais problemas, o Estatuto da Terra preconiza a implementação da reforma agrária, que não significa, ao contrário do divulgado por setores retrógrados, uma forma de expropriação de terras para doação a pessoas mal intencionadas, mas sim um meio de promover o incremento da produtividade através da melhor organização da estrutura fundiária.

Veja-se como a superfície pode contribuir para tal fim.

É sabido que o principal instrumento para a implementação da reforma agrária repousa na desapropriação para fins de assentamento. Todo esse processo, contudo, a par de complexo e demorado, afigura-se extremamente oneroso, na medida em que a desapropriação, somente realizável com o pagamento do valor venal do imóvel, impõe ao 
Estado o pagamento de um preço. Como os imóveis de interesse para a reforma agrária devem ostentar grandes dimensões, decorre que a indenização paga ao proprietário é sempre vultosa. Nesse passo, dados oriundos do INCRA atestam que o custo para o assentamento de uma família pode chegar aos quarenta mil reais (MARQUESI, 2001, p.147). Como o objetivo do atual governo é o de assentar trezentas mil unidades familiares, só aqui se tem uma cifra próxima a doze bilhões de reais.

Ora, se, ao invés de promover a desapropriação, o Estado impusesse a superfície aos imóveis não cumpridores da função social, tal desembolso seria substancialmente reduzido. A somo, assim economizada, poderia ser empregada em outros setores da agropecuária, como o incremento dos financiamentos rurais, projetos de irrigação, pesquisa e desenvolvimento de novas variedades de culturas, subsídios à maneira européia ou norteamericana, dentre outros propósitos.

No fundo, tem-se modelo semelhante ao da enfiteuse. Contudo, a superfície traz a vantagem, sem dúvida ponderável, de não ser perpétua, o que significa que o dono do solo, cedo ou tarde, recuperará o domínio pleno. Com a produtividade do imóvel, antes ocioso e agora funcional, surgem efeitos salutares, como o melhor abastecimento do mercado primário, o recolhimento de impostos, a redução dos conflitos no campo e o bem-estar do possuidor, tudo seguindo o norte do art. 186 do Texto Constitucional.

Poder-se-á argumentar que tais escopos podem ser igualmente atingidos com o arrendamento. Contudo, a superfície ainda aqui traz vantagens, porque implica a transmissão da propriedade ao superficiário. Este promoverá acessões no imóvel, instalando construções e plantações, na certeza de que, sendo proprietário, poderá delas dispor, seja alienando-as seja gravando-Ihes de garantia, como um penhor ou uma hipoteca (BRAGA TEIXEIRA, 1993, p.93). Poder-se-á argumentar, ainda, que o dono do solo ficará privado ao aproveitamento econômico da coisa. Todavia, responde-se afirmando que a privação será temporária e, de qualquer modo, a coisa já se achava ociosa ou mal aproveitada pelo proprietário. Do mesmo modo, e ao contrário do que sustenta Ricardo Aronne (1999, p.268ss), a superfície é mais vantajosa do que a concessão de uso, pela mesma razão de que esta não á atributiva do domínio.

A superfície, mais do que o arrendamento, é atrativa ao possuidor, que pode agora dizer-se proprietário, com todas as vantagens decorrentes de tal titulação, inclusive a 
possibilidade de alienar, circunstância a permitir que a coisa possa ser transferida sucessivas vezes, com um incremento das relações negociais e econômicas.

Outra não é a opinião de Rui Geraldo Camargo Viana (2002):

\begin{abstract}
O Estado deveria se embasar no Direito alemão. Por exemplo, caso ele construísse casas, não precisaria dar todas aos pobres. A nossa reforma agrária é inútil, porque damos terras para os sem-terra. Daqui a pouco, eles vão se transformar em latifundiários. E os próximos sem-terra? O velho Prof. Waldemar Ferreira sabiamente dizia, há 50 anos, naquele tempo do compromisso, que o problema do Brasil não é dar terra ao homem, mas dar o homem à terra. Hoje pergunto: será que é assim? Como está a terra? Está acabando. O problema do Brasil não é só dar terra ao homem. Se assim procedermos, teremos a produção cíclica e não haverá mais terra para dar.
\end{abstract}

Adiante, o Professor das Arcadas (apud VIANA, 2002) sugere:

O Estado construiria grandes campos urbanos e, ao invés de vender ou dar, cederia o direito de superfície. A pessoa ocupa o terreno por certo período e depois transfere para outro, como os judeus, na sua sabedoria, faziam com o ano sabático: emprestavam as terras por certo período e elas iam passando de mão em mão, e a riqueza circulava.

O regime superficiário vem para preencher o espaço deixado pela enfiteuse. Contudo, depura-a, porquanto elimina o problema que a torna obsoleta, vale dizer a perpetuidade. Se o instituto enfitêutico serviu, no passado remoto, para fomentar a ocupação de espaços físicos, a superfície, refinando-a e submetida a princípios e regras cogentes de ordem pública, poderá vir a ser um eficaz mecanismo na implementação da reforma agrária.

\title{
6 Conclusão
}

Disposta pelo Código como um direito real limitado, o instituto da superfície constitui mecanismo bem-vindo no direito brasileiro. Conquanto não seja uma novidade, nem aqui nem em solo europeu, jazeu dormente entre nós desde 1822, quando foi abandonada em favor do regime enfitêutico. Decorridos cento e oitenta anos, ressurge agora para retomar o posto que lhe fora subtraído por aquele regime.

A superfície, uma forma de desdobramento dos poderes dominiais, mostra-se potencialmente hábil a incrementar os escopos sociais da propriedade urbana e rural, 
afigurando-se um bom instrumento de ocupação de espaços ociosos ou mal utilizados. Atende, portanto, aos objetivos sócio-econômico-ambientais da propriedade imobiliária.

Ainda não assimilado pelo tecido social e incipiente na administração pública, o direito real de superfície deverá se converter, em médio prazo, num dos principais mecanismos de urbanificação e de reforma agrária. Tal está a depender, contudo, de regulamentação técnica tanto pelo executivo municipal quanto pelos órgãos fundiários.

Aguardem-se, assim, a iniciativa do Estado e a recepção do instituto pela coletividade.

\section{Referências}

ARONNE, Ricardo J. Por uma Nova Hermenêutica dos Direitos Reais Limitados. Rio de Janeiro: Renovar, 1999.

BEVILÁQUA, Clóvis. Direito das Coisas. 4. ed. Rio de Janeiro: Forense, 1956.

BRAGA TEIXEIRA, J.G. O Direito Real de Superfície. São Paulo: Revista dos Tribunais, 1993.

COSSARI, Nelson. Superfície. Disponível em: <www.acader.unc.edu.ar>. Acesso em: 13 jun. 2005.

FIÚZA, Ricardo. Novo código civil comentado. 4. ed. São Paulo: Saraiva, 2005.

GONDINHO, André O. Função Social da Propriedade, em Problemas de Direito CivilConstitucional. Coord. Tepedino, G.M. Rio de Janeiro: Renovar, 2000.

GROSSI, Paolo. A propriedade e as propriedades na oficina do historiador, em História da Propriedade e outros discursos. Trad. Fritoli, L. E. Rio de Janeiro: Renovar, 2006.

KOJRANSKI, Nelson. Direitos Reais, em O Novo Código Civil. Estudos em Homenagem ao Prof. Miguel Reale. Org. Franciulli Neto et al. São Paulo: LTr, 2003.

MARQUESI, Roberto W. Direitos Reais Agrários e Função Social. Curitiba: Juruá, 2001.

MONTEIRO, Washington B. Curso de Direito Civil. Atual. Maluf, Carlos A. D. 37. ed. São Paulo: Saraiva, 2003. V. 3.

MOREIRA ALVES, J.C. Direito Romano. 13. ed. Rio de Janeiro: Forense, 2004. v. 1. 
VARELLA, Marcelo D. Introdução ao Direito à Reforma Agrária. Campinas: LED, 1998.

VIANA, Rui G. C. O Novo Código Civil Brasileiro. Seminário. Câmara dos Deputados. Brasília, 05.11.02. 
Roberto Wagner Marques, Ana Cláudia C. Zuin Mattos do Amaral e Miriam Odebrecht Carvalho de Mendonça 